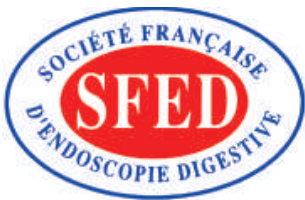

\title{
Guidelines of the French Society for Digestive Endoscopy (SFED)
}

\author{
Management of Patients on Anticoagulants or Antiplatelet Agents \\ before Digestive Endoscopy
}

B. Napoléon ${ }^{1}$

B. Boneu ${ }^{2}$

L. Maillard ${ }^{3}$

C.-M. Samama ${ }^{4}$

J.-F. Schved ${ }^{2}$

G. Gay ${ }^{1}$

T. Ponchon ${ }^{1}$

D. Sautereau ${ }^{1}$

J.-M. Canard ${ }^{1}$

and the Board of the SFED ${ }^{1}$

Managing patients who are taking Vitamin K Antagonists (VKA) or antiplatelet agents (APA) is a common problem before performing digestive endoscopy. Although risks concerning bleeding are the remit of both the gastroenterologist and anaesthetist, the potential risk of interruption of antithrombotic treatment for the patient should not be underestimated. Faced with the wide variety of situations, it is difficult to lay down rules which cover all circumstances and there are few reference guidelines [1-3]. Ideally, changes of treatment ought to be made in consultation with the doctor who initially prescribed the treatment with estimation of the risk/benefit ratio bearing in mind alterations to the antithrombotic treatment. This has to be tailored to individual patients on a case-by-case basis.This ideal situation is rare. Often the patient cannot remember the reference physician or the latter cannot be contacted. Other factors rendering such strategies difficult and complex include differences of opinion or lack of knowledge about the respective risks of stopping antithrombotic treatment or of not performing the endoscopy, lack of data in the literature, etc. However, in practice there are some data on which to base a decision. Three factors should be taken into account: the risk of haemorrhage from the procedure, the antithrombotic treatment used and the risk of thromboembolism when the treatment is withdrawn. In an attempt to reach the broadest possible consensus, the French Society of Digestive Endoscopy (SFED), the Study Group on Haemostasis and Thrombosis (GEHT) of the French Society of Haematology, the French Society of Cardiology (SFC) and the French Society of Anaesthesiology and Intensive Care Medicine (SFAR) have joined forces and put forward these recommendations. Of course, they are still only temporary guidelines and are likely to change over time as scientific knowledge accrues.

\section{Which Procedures Involve the Risk of Haemorrhage?}

There are few data in the literature about the risk of haemorrhage from procedures on patients taking antithrombotics. One may consider that antithrombotic treatment, which prolongs bleeding, increases the usual risk of haemorrhage by rendering symptomatic any bleeding that would have gone unnoticed in a patient with normal coagulation. However, antithrombotic treatment itself does not trigger bleeding. Therefore, when the risk of haemorrhage from a procedure is very low, antithrombotic treatment has little impact. In the absence of available data, three factors come into play when assessing the risk of a procedure on patients undergoing antithrombotic treatment:

- When the risk of spontaneous haemorrhage from a procedure is already high $(>1 \%)$, antithrombotic treatment is likely to increase it. The risk of haemorrhage from a sphincterotomy is thus multiplied by 7.8 on VKA [4].

- When there is a risk of bleeding which cannot be accessed by endoscopic haemostasis (endoscopic ultrasound fine-needle aspiration (EUS-FNA)...), the frequency and in particular the severity of the risk of haemorrhage may be increased.

- When there is a high risk of perforation, antithrombotic therapy may complicate the treatment.

Institution

${ }^{1}$ Société Française d'Endoscopie Digestive (SFED)

${ }^{2}$ Groupe d'Etude de l'Hémostase et de la Thrombose (GEHT)

${ }^{3}$ Société Française de Cardiologie (SFC)

${ }^{4}$ Société Française d'Anesthésie et de Réanimation (SFAR)

Corresponding Author

Dr. B. Napoleon · Société Française d'Endoscopie Digestive (SFED) · 35 rue Bataille · 69008 Lyon · France .

Phone: +33-478-78-10-51 · Fax: +33-478-74-07-92 · E-mail: bertrand.napoleon@libertysurf.fr

Bibliography

Endoscopy 2006; 38 (6): 632-638 ๔ Georg Thieme Verlag KG Stuttgart · New York

DOI 10.1055/s-2006-925086 · Published online 14 March $2006 \cdot$ ISSN 0013-726X 
So, two groups can be identified:

\section{A Low-risk Procedures: Exceptional Bleeding with Possible Control by Endoscopy}

1. oral gastroscopy,

2. rectosigmoidoscopy

3. colonoscopy without polypectomy,

In the special case of colonoscopy, one rarely knows before the procedure if a polyp resection will be necessary. Moreover, the risk of perforation from the examination can make it more risky to continue with antithrombotic therapy in cases of emergency surgery. More often than not these two factors place colonoscopy in the category of at-risk procedures, in order to remain prudent.

5. diagnostic endoscopic retrograde cholangiopancreatography (ERCP), ERCP with dilatation of ampulla or bile duct [5], ERCP with stent insertion without sphincterotomy

6. enteroscopy,

7. during these exploratory procedures, carrying out biopsies, whether with standard or paediatric forceps, does not increase the risk significantly [6].

\section{B High-risk Procedures}

High risk of bleeding ( $>$ or equal to $1 \%$ ) with possibility of endoscopic control of haemorrhage:

1. Tissue resection (not by a biopsy):

colonic polypectomy (1-2.5\%) [7], gastric macrobiopsy with loop polypectomy and gastric polypectomy (4\%) [8], mucosectomy (up to $22 \%$ ) [9], ampullectomy (8\%) [10] ...

2. endoscopic sphincterotomy $(2.5-5 \%)[4,11]$

3. laser photodestruction and photocoagulation (up to 6\%) [12]

4. endoscopic treatment of oesophageal or gastric varices (up to $6 \%)[13,14]$

5. haemostatic procedures on vascular lesions (up to 5\%) [15]

Low risk of bleeding ( $<1 \%$ ) but without the possibility of endoscopic control:

1. EUS-FNA [16],

2. percutaneous gastrostomy [17],

3. treatment of digestive stenosis by dilatation (pneumatic or balloons) or by insertion of metal stent without dilatation $[18,19]$

4. nasal gastroscopy (risk of epistaxis) [20]

\section{What is the Risk of Haemorrhage from Antithrombotic} Therapy?

\section{A Antiplatelet Agents (APA)}

They inhibit platelet function (particularly activation and aggregation)

\section{Aspirin and non-steroidal anti-inflammatory drugs (NSAIDs)}

Aspirin and most NSAIDs restrict platelet aggregation. Aspirin brings about irreversible inhibition of cyclo-oxygenase. The doses normally used vary from 75 to $325 \mathrm{mg} / \mathrm{d}$ (1 - $2 \mathrm{mg} / \mathrm{kg}$ in practice) [21]. Disturbed primary haemostasis is only fully corrected when all the platelets have been renewed, that is after 7 to 10 days. However, a figure of $50 \mathrm{G} / \mathrm{l}$ of functional platelets is regarded as sufficient for a normal haemostatic effect [22]. About $10 \%$ of the platelet pool is renewed per day [21]. So, according to the basic platelet count, stopping the treatment for 3 to 5 days is usually sufficient for the patient to recover normal haemostatic function. NSAIDs also inhibit cyclo-oxygenase but this is reversible. The duration of effect is temporary and directly dependent on the medication's half-life. Only flurbiprofen (CEBUTID ${ }^{\circledR}$ ) has a marketing licence as an antiplatelet agent. It has proved to be effective in reducing the risk of rethrombosis after successful coronary repermeabilisation following myocardial infarction [23].

The results published to date, although few, suggest that aspirin and NSAIDs, at standard doses, do not significantly increase the risk of bleeding after an endoscopy with biopsies [6,24], after a snare colonic polypectomy [24-26] and after a biliary sphincterotomy $[11,27]$. In the case of snare colonic polypectomy, the use of an endoloop is still recommended as soon as the insertion pedicule is more than a centimetre. There are no available data on polyp resection on aspirin using the mucosectomy method. There are also insufficient data on the other high-risk procedures.

There have been few studies on the risk of perioperative haemorrhage during digestive surgery. In the case of NSAIDs, no studies have shown an increase in the number of transfused patients [28], particularly when they were prescribed as analgesics [29]. It is also accepted that the risk from aspirin is low [30], so that emergency digestive surgery can be carried out without prophylactic transfusion of platelets [22].

\section{Thienopyridines: ticlopidine (TICLID $\left.{ }^{\circledR}\right)$ and clopidogrel (PLAVIX ${ }^{\circledR}$ )}

These substances cause irreversible blocking of one of the adenosine diphosphate (ADP) platelet receptors. In the event of bleeding, platelet transfusion may be necessary [22]. Although they often cause an increase in bleeding time, there is currently no test which can determine when platelet function returns to normal. When interruption is being considered, it is advisable to wait for the platelet regeneration in 7 to 10 days. However, as with aspirin, 3 to 5 days may be enough for normal haemostatic function to recover (see above). Although comparative studies on aspirin and thienopyridines have not shown any difference in risk of haemorrhage [31], there are currently not enough data to extrapolate the recommendations concerning aspirin to these products [32]. The same applies to perioperative risk of haemorrhage: although there are few studies, the risk is regarded as considerable with a high incidence of postoperative bleeding [33].

\section{Dipyridamole}

This substance only has a modest antiplatelet effect which does not increase the risk of haemorrhage.

\section{B Vitamin K Antagonists}

These are the only oral anticoagulant treatments currently available. Their plasma half-life varies depending on the product used but coagulation theoretically returns to normal after they have been completely withdrawn for 2 to 4 days, depending on the substance. Anticoagulation is dependent on the dose used and the susceptibility of the individual. The International Normalised Ratio (INR) is a good reflection of the anticoagulation obtained. 
The risk of haemorrhage increases at the same time as INR increases. An INR between 2 and 3 is generally desirable for effective anticoagulation and involves a minimal risk of haemorrhage. An INR between 3 and 4.5 is necessary if there is a major risk of thromboembolism. When the INR does not exceed 1.5, the risk of haemorrhage is the same as that of untreated patients. In the event of overdosage (INR $>6$ ) and/or bleeding, there are several potential courses of action [34]. If there is no bleeding, withdrawal of VKA and the oral administration of vitamin K1 should be adjusted to the increase in INR. In the event of a haemorrhage, i.v. injection of vitamin $\mathrm{K} 1$ and perfusion of Prothrombin Complex Concentrates (Kaskadil ${ }^{\circledR}$ ) should be discussed.

\section{Heparins}

Heparins are the third family of antithrombotic drugs which are normally used. The main indications are the prevention and curative treatment of venous thromboembolic disease (VTE) (including deep vein thrombosis and pulmonary embolism), unstable angina and the prevention of thrombosis with cardiac valve prosthesis before replacement by VKA. To prevent VTE, only low molecular weight heparins (LMWH) are used in practice, at low doses of $1750 \mathrm{U}$ to $5000 \mathrm{U}$ once a day, according to the level of risk of thromboembolism and the product used. At these doses, the risk of haemorrhage is low and becomes negligible 12 hours after administration. Concerning the other indications, either LMWH administered subcutaneously or unfractionated heparin (UH) administered intravenously in a continuous perfusion or subcutaneously (Calciparine ${ }^{\circledR}$ ) are used. The doses of LMWH in these cases are between $80 \mathrm{U}$ and $100 \mathrm{U} / \mathrm{kg}$ twice a day or between 160 and $175 \mathrm{U} / \mathrm{kg}$ once a day depending on the substance used. If the LMWH is administered twice a day, 12 to 18 hours must be allowed for the level of heparinaemia to become compatible with normal haemostasis again. If the LMWH is administered once a day, this waiting period should be extended to 24 hours. It should be noted that the activated partial thromboplastin time (APTT) is no use here as it remains normal even though heparinaemia is still high. The only way of knowing if there is residual heparinaemia is to evaluate the anti-Xa activity which must be less than $0.20 \mathrm{U} / \mathrm{ml}$. In the case of UH administered as an i.v. perfusion at a dose of 400 to $600 \mathrm{U} / \mathrm{kg} / 24 \mathrm{~h}$, the half-life is between 45 and 90 minutes. Heparinaemia is compatible with normal haemostasis $4 \mathrm{~h}$ to $6 \mathrm{~h}$ after the perfusion is stopped. Here, APTT can be useful to validate normalisation of haemostasis. If serum heparin levels are measured it must be less than $0.10-0.20 \mathrm{U} / \mathrm{ml}$. If $\mathrm{UH}$ is administered subcutaneously in 3 or 2 injections, one has to wait, owing to the longer halflife, for the $8^{\text {th }}$ or the $12^{\text {th }}$ hour until heparinaemia is compatible with normal haemostasis. Here again, APTT can be used to monitor the anticoagulation status.

\section{New Antithrombotic Drugs}

New antithrombotic drugs have recently become available: a drug with anti-Xa activity, fondaparinux (Arixtra ${ }^{\circledR}$ ) and another, not antithrombin-dependent, with direct antithrombin activity called ximelagatran (Exanta ${ }^{\circledR}$ ). They are used to prevent deep vein thrombosis after orthopaedic surgery. Their risk of haemorrhage does not seem very different from that of LMWH. There is no known antidote if a haemorrhage occurs. Their half-life is 2 to 3 hours for ximelagatran and at least 17 hours for fondaparinux. One should preferably wait until the product is eliminated ( 4 to 5 half-lives) before performing an endoscopy. In the event of an emergency procedure, the indication should be discussed with the prescribing doctor.

\section{What are the Risks of Withdrawing Antithrombotic Therapy?}

Depending on the therapeutic indications, the risk of thromboembolism may prove to be major, average or minor if treatment is withdrawn. Cases of sudden death or stent occlusion have been reported in the week following the withdrawal of antithrombotic treatment $[35,36]$.

\section{A Patients on VKA}

\section{Indications with a major risk of thromboembolism [37]}

- Most mechanical valve prostheses: all mitral and first generation aortic prostheses; $2^{\text {nd }}$ generation aortic prostheses if there is another risk factor for embolism [37]. Anticoagulation with an INR between 3 and 4.5 is recommended.

- Atrial fibrillation (AF) combined with other risk factors for thromboembolism, particularly mitral valvular disease [37]. Anticoagulation with an INR between 2 and 3 is normally used.

In these cases, VKA must be replaced and anticoagulation should be ajusted according to a particular regime (Table $\mathbf{1}$ ) using a UH. The indications should be carefully evaluated and treatment options should be reconsidered (surgery vs. endoscopy) and preference given to endoscopic procedures involving the least risk of haemorrhage (insertion of a biliary stent without sphincterotomy ...).

Table 1 Patients on VKA

1) replacement in the event of major risk of thromboembolism: - withdrawal of VKA on D-3 (acenocoumarol : SINTROM ${ }^{\circledR}$ ), D-4 ( fluindione: PREVISCAN ${ }^{\circledR}$ ), D-5 (warfarine : COUMADINE ${ }^{\circledR}$ ) or D-6 (phenprocoumone: MARCOUMAR ${ }^{\circledR}$ ) before procedure

- on the day after VKA is withdrawn, start heparin at an anticoagulating dose (check by heparinaemia and/or APTT)

- Check INR the day before the examination

- withdrawal of the continuous perfusion of heparin 4 to 6 hours before the procedure or last injection of calcium heparin $8 \mathrm{~h}$ before (3 injections/day) or $12 \mathrm{~h}$ before ( 2 injections/day); resumption of heparin 6 to 8 hours after the procedure or immediately if the risk of haemorrhage is inexistant

- resumption of VKA on the same evening (or later, see below)

- withdrawal of the heparin when adequate INR is achieved for 2 consecutive days

2) replacement in the event of moderate risk of thromboembolism:

a) replacement by UH: id. to the major risk of thromboembolism

b) replacement by LMWH insofar as it is legally permitted for the treatment of the current disease (VTE, unstable angina)

- withdrawal of VKA on D-3 (acenocoumarol : SINTROM ${ }^{\circledR}$ ), D-4 (fluindione : PREVISCAN ${ }^{\circledR}$ ), D-5 (warfarine : COUMADINE ${ }^{\circledR}$ ) or D-6 (phenprocoumone : MARCOUMAR $^{\circledR}$ ) before procedure

- introduction of LMWH at curative doses the next day

- withdrawal of LMWH on D-1 with a control of haemostasis (INR, platelets)

- resumption of LMWH 12 hours after the procedure

- resumption of VKA on the same evening (or later see below)

- withdrawal of the LMWH when INR on 2 consecutive days is between 2 and 3 . 
Indications with a moderate risk of thromboembolism [37]

- prevention and/or treatment of VTE,

- AF in patients over 65 or in patients with associated risk factors of thromboembolism (history of stroke, cardiac decompensation less than 2 months prior to endoscopy, or left ventricular dilatation (telediastolic diameter of the LV more than $60 \mathrm{~mm}$ ),

- certain cases of mitral regurgitation or stenosis (dilatation of the left atrium),

- mechanical valvular aortic prostheses in the absence of an embolic risk cofactor,

- valvular bio-prostheses following implantation surgery (first months).

Replacement of antithrombotic treatment (Table $\mathbf{1}$ ) is usually justified.

\section{B Patients on APA}

\section{Indications with a major risk of thromboembolism [38 -40]}

- Acute coronary syndromes in the previous month

- Implantation of a bare metal stent in the previous month

- Implantation of a drug eluting stent in the previous 2 months for sirolimus (Cypher) stents and in the previous 6 months for paclitaxel (Taxus) stents

- Implantation of a PTFE covered stent (coated Jo stent) in the previous year

- Endocoronary radiotherapy in the previous year

In these cases, APA must be replaced and this must be performed after specialist consultation (UH only, LMWH at curative doses only or combination of LMWH at curative doses + flurbiprofen). The indications should be carefully weighed up, treatment options should be reconsidered (surgery vs. endoscopy) and preference given to endoscopic procedures involving the lesser risk of haemorrhage (insertion of a biliary stent without sphincterotomy...).

\section{Indications with a moderate risk of thromboembolism [32]}

- acute coronary syndrome more than 1 month prior to endoscopy or stable angina,

- secondary prevention of myocardial infarct or arteritis,

- secondary prevention of stroke in patients with no emboligenic cardiopathy,

- AF in patients under 65 with no risk factor for thromboembolism and no emboligenic cardiopathy.

Replacement of antithrombotic treatment (Table 2) is usually justified.

\section{Indications with a minor risk of thromboembolism}

This mainly concerns primary prevention by APA of the risk of death and myocardial infarct in subjects over 50 who have at least one vascular risk factor [32].

Withdrawal of treatment may be considered.

\section{Table 2 Patients on APA}

1) replacement in the event of a major risk of thromboembolism: Given the importance of the risk of thrombosis when APA are withdrawn and the short duration of treatment, it is better to postpone a high-risk endoscopic procedure. If the procedure appears to be essential, the substitution should be made after specialist advice (UH only, LMWH at curative doses only or combination of LMWH at curative doses + CEBUTID).

2) replacement in the event of a moderate risk of thromboembolism: a) replacement by $C E B \cup T I D^{\circledR}$ :

- withdrawal of APA according to the product's half-life (7 to 10 days) or according to the time required to resume adequate aggregation function (i.e. $50 \mathrm{G} / \mathrm{l}$ of functional platelets, being renewed at a rate of $10 \%$ of the initial platelet number per day).

- start the CEBUTID ${ }^{\circledR}$ (50 mg morning and evening) on the day after APA withdrawal

- withdraw the CEBUTID ${ }^{\circledR} 24$ hours before the procedure

- resume the APA on the day after the procedure (or later see below)

b) replacement by $L M W H$

- withdrawal of APA according to the product's half-life (7 to 10 days) or according to the time required to resume adequate aggregating function (i.e. 50G/l of functional platelets, being renewed at a rate of $10 \%$ of the initial platelet number per day).

- on the day after antiplatelet agents are withdrawn, introduce a LMWH at curative doses

- withdraw the LMWH on D-1 with a check on haemostasis

- resume the APA on the day after the procedure (or later see below)

\section{Treatment Substitution?}

No drug has been given a specific marketing licence for substituting VKA or APA. The replacement should be adapted for the treatment used (VKA or APA) and the risk of thromboembolism (Tables $\mathbf{1}$ and $\mathbf{2}$ ).

VKA is normally replaced by a $\mathrm{UH}$ at curative doses (400 to $600 \mathrm{IU} / \mathrm{kg} / 24 \mathrm{~h}$ ). Heparin in a continuous perfusion is still the standard method [34]. Calcium heparin (calciparine ${ }^{\circledR}$ subcutaneously) is a possible alternative. The total dose required per 24 hours (expressed in units) is equal to or slightly above the dose needed for continuous perfusion. It may be divided into 2 or 3 subcutaneous daily injections. The effectiveness of treatment should be evaluated by measuring the APTT or the heparin levels [34]. The APTT is used most often: taken between two subcutaneous injections, it must be 2 to 3 times that of the control. Heparinaemia must be between 0.3 and $0.6 \mathrm{IU} / \mathrm{L}$. In the event of disparity between the injected dose of UH and the result of APTT, it is advisable to measure heparinaemia. It is accepted that replacement using LMWH is effective [41]. A protocol has also been proposed by the SFC as a possible alternative to replacement by $\mathrm{UH}$. Its prescription, however, remains the responsibility of the prescribing doctor. When a LMWH is chosen, it must be used at curative doses in 1 or 2 daily subcutaneous injections, depending on the product. The dose is adjusted to the patient's weight. As with UH, platelets need to be monitored in order to detect any thrombopenia. No other systematic biological monitoring is recommended except in the case of elderly patients, patients with kidney failure or when there is a risk of haemorrhage [34]. It is useful to measure anti-Xa activity in order to assess whether there is an accumulation of LMWH. The target level will depend on the LMWH used. 
APA may be replaced with substances which are reversible and with short-term antithrombotic effects. However, no treatment has been validated for the time being. Flurbiprofen (CEBUTID ${ }^{\circledR}$ ), a dose of $50 \mathrm{mg}$ twice a day, with an anti-aggregating effect that is reversible in 24 hours is sometimes used, although its effectiveness has not been officially proved. Withdrawal should be done 24 hours before the procedure. LMWH which, at curative doses and combined with aspirin, have proved effective in some treatments of acute coronary syndrome, are an alternative [32]. They are used according to the same regime as that used for VKA replacements.

\section{Resumption of Antithrombotic Treatment}

Although bleeding is usually early (within the first 24 hours after the procedure), it can also be delayed (up to 3 weeks later, when the polypectomy scare is sloughed off). Delayed bleeding can be increased by resuming antithrombotics at an early stage. After a sphincterotomy, for example, the risk of bleeding is estimated between 10 and $15 \%$ if the VKA are resumed before the $3^{\text {rd }}$ day [27]. There are no other data in the literature on which recommendations can be based. Treatment will need to be resumed on a case-by-case basis, depending on the patient's risk of thromboembolism.

\section{Recommendations}

\section{A General}

1. When antithrombotic treatment is temporary and endoscopic procedures are considered high-risk and not urgent, postponement of the endoscopic exploration must be suggested.

2 . In emergencies and when antithrombotic treatment is uninterrupted and/or needs to be resumed early, preference must be given to the use of endoscopic techniques which limit the risks of haemorrhage: endoloop, haemostatic clips, placement of biliopancreatic prostheses without sphincterotomy, etc. The equipment for carrying out a local haemostatic procedure during endoscopy must be available. The use of a pharmacological antagonist or a blood derivative for inhibiting the effect of the antithrombotic treatment must be discussed, taking the endoscopic alternatives and the relative risk of thromboembolism into account.

3. When, in an emergency, the patient's risk of thromboembolism is not known, caution should be exercised and the patient regarded as being at high risk of thromboembolism.

\section{B Adapting the Treatment to Situations (Table 3) High-risk procedures}

a) High risk of bleeding ( $>$ or equal to $1 \%$ ) with possibility of control by endoscopy:

- When there are no haemostatic problems, colonoscopy with loop polypectomy and sphincterotomy can be performed with the patient on aspirin and standard doses of NSAID. In the case of colonic polypectomy, the use of an endoloop is recommended when the base of the polyp is $>1 \mathrm{~cm}$; the mucosectomy method is not recommended with aspirin.

- Except for these special circumstances, antithrombotic treatment must be stopped before the procedure for the length of time needed to inactivate them. For VKA, blood tests must be performed before the procedure to ensure that the INR has returned to normal.

b) Low risk of bleeding ( $<1 \%)$ with no possibility of haemostatic control by endoscopy:

All antithrombotic treatments must be stopped before the procedure for the length of time needed to inactivate them. For VKA, blood tests must be performed before the procedure to ensure that the INR has returned to normal.

Table 3 Adapting the treatment to situations

\begin{tabular}{|c|c|c|c|}
\hline & NSAID, aspirin & VKA & other antithrombotics \\
\hline oral gastroscopy +/- biopsies & yes & recent INR & yes \\
\hline rectosigmoidoscopy +/- biopsies & yes & recent INR & yes \\
\hline colonoscopy without polypectomy + /- biopsies & yes & recent INR & yes \\
\hline diagnostic EUS, & yes & recent INR & yes \\
\hline ERCP without sphincterotomy $+/$ - biopsies & yes & recent INR & yes \\
\hline enteroscopy +/- biopsies & yes & recent INR & yes \\
\hline colonoscopy with polypectomy & yes & no & no \\
\hline ERCP with endoscopic sphincterotomy & yes & no & no \\
\hline gastric macrobiopsy and gastric polypectomy & no & no & no \\
\hline mucosectomy, ampullectomy & no & no & no \\
\hline laser photodestruction and photocoagulation & no & no & no \\
\hline treatment of oesophageal or gastric varices & no & no & no \\
\hline haemostatic procedures on vascular lesions & no & no & no \\
\hline EUS-FNA and EUS-guided therapy (e.g., drainage procedures) & no & no & no \\
\hline percutaneous gastrostomy & no & no & no \\
\hline dilatation of digestive stenosis & no & no & no \\
\hline metal digestive prostheses insertion without dilatation & no & no & no \\
\hline nasal gastroscopy & no & no & no \\
\hline
\end{tabular}

yes: possible without stopping or replacing antithrombotic treatment

recent INR: possible without stopping or replacing treatment if INR is not excessive

no: replacement or withdrawal of antithrombotic treatment necessary except in special cases 


\section{Low-risk procedures}

Anticoagulant or antiplatelet therapy does not need to be adjusted. The INR should have been estimated recently for patients on VKA. A non-urgent procedure will need to be postponed if anticoagulation is above recommended levels.

\section{Replacement and Resumption of Treatment Treatment should be replaced according to the risk of thromboembolism}

- in patients at major risk:

During the period the treatment is withdrawn, an appropriate antithrombotic treatment should be introduced and monitored.

- in patients at average risk:

During the period the treatment is withdrawn, an appropriate antithrombotic treatment should be discussed on a case-bycase basis and monitored.

- in patients at minor risk:

Replacement is unnecessary.

\section{Antithrombotic treatment should be resumed after the procedure.}

In view of the risk of delayed bleeding, the benefit of immediate resumption must be weighed against the increased risk of haemorrhage. Treatment needs to be adjusted on a case-by-case basis.

\section{Conclusion}

Drawing up recommendations for the management of patients on antithrombotics before digestive endoscopy is difficult because of the various situations encountered and the absence of formal scientific answers to many questions. The respective risks of the procedure (risk of haemorrhage) and of the underlying disease (risk of thromboembolism) must be considered on a caseby-case basis. There should be close collaboration between the prescribing physician, the anaesthetist and the gastroenterologist. Such situations also afford questioning certain cases of long-term antithrombotic treatment which may not be currently indicated and indeed inappropriate prescribing of endoscopic procedures. The consensus reached by the societies concerned involved in this work could be used as a starting point for debate. However, one should remember that some of the choices made are arbitrary and, in any case, are likely to change as time goes by.

\section{Acknowledgement}

We want to thank Dermot O'Toole who reviewed the manuscript for English corrections.

\section{References}

${ }^{1}$ Guideline on the management of anticoagulation and antiplatelet therapy for endoscopic procedures. Gastrointest Endosc 2002; 55 : $775-779$

2 Miller AM, McGill D, Bassett ML. Anticoagulant therapy, antiplatelet agents and gastrointestinal endoscopy. J Gastroenterol Hepatol 1999; 14: $109-113$
${ }^{3}$ Hittelet A, Devière J. Management of anticoagulants before and after endoscopy. Can J Gastroenterol 2003; 17: 329-332

${ }^{4}$ Nelson DB, Freeman ML. Major hemorrhage from endoscopic sphincterotomy : risk factor analysis. J Clin Gastroenterol 1994; 19: 283-287 ${ }^{5}$ Bergman JJ, Rauws EA, Fockens P, vanBerkel AM, Bossuyt PM, Tijssen JG et al. Randomised trial of endoscopic balloon dilation versus endoscopic sphincterotomy for removal of bileduct stones. Lancet 1997; 349: $1124-1129$

${ }^{6}$ O'Laughlin JC, Hoftiezer JW, Mahoney JP, Ivey KJ. Does aspirin prolong bleeding from gastric biopsies in man? Gastrointest Endosc 1981; 27: $1-5$

${ }^{7}$ Waye J. Colonoscopy. CA Cancer J Clin 1992; 42: 350- 365

${ }^{8}$ Remine SG, Hughes RW, Weiland LH. Endoscopic gastric polypectomy. May Clin Proc 1981; 56: 371 - 375

${ }^{9}$ Ahmad NA, Kochman ML, Long WB, Furth EE, Ginsberg GG. Efficacy, safety, and clinical outcomes of endoscopic mucosal resection: a study of 101 cases. Gastrointest Endosc 2002; 55: 390-396

${ }^{10}$ Binmoeller KF, Boaventura S, Ramsperger K, Soehendra N. Endoscopic snare excision of benign adenomas of the papilla of Vater. Gastrointest Endosc 1993; 39: 127-131

${ }^{11}$ Cotton PB, Lehman G, Vennes J, Geenen JE, Russel RC, Meyers WC et al. Endoscopic sphincterotomy complications and their management : an attempt at consensus. Gastrointest Endosc 1991; 37: 383-393

${ }^{12}$ Mathus-Vliegen EM, Tytgat GN. Nd:YAG laser photocoagulation in colorectal adenoma. Evaluation of its safety, usefulness and efficacy. Gastroenterology 1986; 90: 1865-1873

${ }^{13}$ Piai G, Cipolletta L, Claar M, Marone G, Bianco MA, Forte G et al. Prophylactic sclerotherapy of high rish esophageal varices : results of a multicentric prospective controlled trial. Hepatology 1988; 8: 14951507

${ }^{14}$ Stiegmann GV, Goff JS, Michaletz-Onody PA, Korula J, Lieberman D, Saeed ZA et al. Endoscopic sclerotherapy as compared with endoscopic ligation for bleeding esophageal varices. N Engl J Med 1992; 326: $1527-1532$

${ }^{15}$ Jensen DM. Endoscopic control of non variceal upper gastrointestinal hemorrhage. In: Yamada T, Alpers DH, Laine L, Owyang C, Powell DW (eds). Textbook of gastroenterology. Philadelphia: Lippincott Williams and Wilkins, 1999: 2857-2879

${ }^{16}$ Napoléon B. Ponction sous échoendoscopie: un geste utile ou dangereux? Gastroentérol Clin Biol 1999; 23: 459-462

${ }^{17}$ Larson DE, Burton DD, Schroeder KW, DiMagno EP. Percutaneous endoscopic gastrostomy. Indications, success, complications, and mortality in 314 consecutive patients. Gastroenterology 1987; 93: 48-52

${ }^{18}$ Neuhaus H, Hoffman W, Dittler HJ, Niedermeyer HP, Classen M. Implantation of self-expanding esophageal metal stents for palliation of malignant dysphagia. Endoscopy 1992; 24: 405-410

${ }^{19}$ Faigel DO. Endoscopy for the diagnosis and management of esophageal cancer. ASGE Clinical Update 2000; 8: 1 - 4

20 Dumortier J, Napoléon B, Hedelius F, Pellissier PE, Leprince E, Pujol B et al. Unsedated transnasal EGD in daily practice: Results with 1100 consecutive patients. Gastrointest Endosc 2003; 57: 198-204

${ }^{21}$ Patrono C, Coller B, Dalen JE, FitzGerald GA, Fuster V, Gent M et al. Platelet-active drugs: the relationships among dose, effectiveness, and optimal therapeutic range. Chest 2001; 119 (1 Suppl): 39S-63S

22 Samama CM, Djoudi R, Lecompte T, Nathan-Denizot N, Schved JF and the AFSSAPS expert group. Perioperative platelet transfusion: recommendations of the Agence française de sécurité sanitaire des produits de santé (AFSSaPS) 2003. Can J Anesth 2005; 52: 30-37

${ }^{23}$ Brochier ML for the Flurbiprofen French Trial. Evaluation of flurbiprofen for prevention of reinfarction and reocclusion after successful thrombolysis or angioplasty in acute myocardial infarction. Eur Heart J 1993; 14: 951 - 957

${ }^{24}$ Shiffman ML, Farrel MT, Yee YS. Risk of bleeding after endoscopic biopsy or polypectomy in patients taking aspirin or other NSAIDs. Gastrointest Endosc 1994; 40: 458-462

${ }^{25}$ Hui AJ, Wong RMY, Ching JYL, Hung LCT, Chung SCS, Sung JJY. Risk of colonoscopy polypectomy bleeding with anticoagulants and antiplatelet agents : analysis of 1657 cases. Gastrointest Endosc 2004; 59: $44-48$

${ }^{26}$ Yousfi M, Gostout CJ, Baron TH, Hernandez JL, Keate R, Fleischer DE, Sorbi D. Postpolypectomy lower gastrointestinal bleeding: potential role of aspirin. Am J Gastroenterol 2004; 99: 1785 - 1789

${ }^{27}$ Freeman ML, Nelson DB, Sherman S, Haber GB, Herman ME, Dorsher PJ et al. Complications of endoscopic biliary sphincterotomy. N Eng J Med 1996; 335: 909-918 
28 Rogers JE, Fleming BG, Macintosh KC, Johnston B, Morgan-Hughes JO. Effect of timing of ketorolac administration on patient-controlled opiod use. Br J Anaesth 1995; 75: $15-18$

${ }^{29}$ Strom BL, Berlin JA, Kinman JL, Spitz PW, Hennessy S, Feldman H et al. Parenteral ketorolac and risk of gastrointestinal and operative site bleeding. A postmarketing surveillance study. Jama 1996; 275: 376 382

${ }^{30}$ Ferraris VA, Swanson E. Aspirin usage and perioperative blood loss in patients undergoing unexpected operations. Surg Gynecol Obstet 1983; 156: 439-442

${ }^{31}$ CAPRIE Steering Committee. A randomised, blinded trial of clopridrogel versus aspirin in patients at risk of ischemic events. Lancet 1996; 348: $1329-1339$

${ }^{32}$ Conférence d'experts: Société Française d'Anesthésie et de Réanimation, Groupe d'étude sur l'hémostase et la thrombose de la société française d'hématologie. Agents antiplaquettaires et période périopératoire. Paris: Elsevier, 2002: 7-139

${ }^{33}$ Kaluza GL, Joseph J, Lee JR, Raizner ME, Raizner AE. Catastrophic outcomes of noncardiac surgery soon after coronary stenting. J Am Coll Cardiol 2000; 35: 1288 - 1294

${ }^{34}$ Boneu B, Schved JF, Lecompte T, Alessi MC et le groupe d'études sur l'hémostase et la thrombose. Utilisation des traitements antithrombotiques en pratique médicale courante. STV numéro spécial 2000; 12 : $2-55$

35 Orford JL, Lennon R, Melby S, Fasseas P, Bell MR, Rihal CS et al. Frequency and correlates of coronary stent thrombosis in the modern era: analysis of a single center registry. J Am Coll Cardiol 2002; 40: $1567-1572$
${ }^{36}$ Leon MB, Baim DS, Popma JJ, Gordon PC, Cutlip DE, Ho KK et al. A clinical trial comparing three antithrombotic-drug regimens after coronary-artery stenting. Stent Anticoagulation Restenosis Study Investigators. N Engl J Med 1998; 339: 1665-1671

${ }^{37}$ Recommandations de la Société Française de Cardiologie concernant les indications et la surveillance des traitements par anticoagulants oraux. AMC 1997; 9: 1289-1305

${ }^{38}$ Steinhubl SR, Berger PB, Mann JT 3rd, Fry ET, DeLago A, Wilmer C et al. CREDO investigators. Clopidogrel for the reduction of events during observation. Early and sustained dual oral antiplatelet therapy following percutaneous coronary intervention: a randomized controlled trial. Jama. 2003; 289: 987

${ }^{39}$ Waksman R, Ajani AE, White RL, Pinnow E, Dieble R, Bui AB et al. Prolonged antiplatelet therapy to prevent late thrombosis after intracoronary gamma-radiation in patients with in-stent restenosis: Washington Radiation for In-Stent Restenosis Trial plus 6 months of clopidogrel (WRIST PLUS). Circulation 2001; 103: 2332-2335

40 Morice MC, Serruys PW, Sousa JE, Fajadet J, Ban Hayashi E, Perin M et al RAVEL Study Group. Randomized study with the Sirolimus-Coated Bx velocity balloon-expandable stent in the treatment of patients with de novo native coronary artery lesions. A randomized comparison of a sirolimus-eluting stent with a standard stent for coronary revascularization. N Engl J Med 2002; 346: $1773-1780$

${ }^{41}$ Stein PD, Alpert JS, Bussey HI, Dalen JE, Turpie AG. Antithrombotic therapy in patients with mechanical and biological prosthetic heart valves. Chest 2001; 119 (1 Suppl): 220S-227S 